\title{
Comparison of body fat in patients with schizophrenia and normal
} controls

\author{
Konstantinos Fountoulakis*1, Melina Siamouli ${ }^{1}$, Panagiotis Panagiotidis ${ }^{1}$, \\ Stamatia Magiria ${ }^{1}$, Stavroula Sokolaki ${ }^{1}$, Sotiris Kantartzis ${ }^{1}$, \\ Natalia Papastergiou ${ }^{1}$, George Shoretsanitis ${ }^{1}$, Evangelia Kouidi², \\ Stergios Kaprinis ${ }^{1}$, Theoharis Mavridis ${ }^{1}$, Apostolos Iacovides ${ }^{1}$ and \\ George Kaprinis ${ }^{1}$
}

Address: ${ }^{13 r d}$ Department of Psychiatry, Aristotle University of Thessaloniki, Greece and ${ }^{2}$ Laboratory of Sports Medicine, Aristotle University of Thessaloniki, Greece

* Corresponding author

from International Society on Brain and Behaviour: 3rd International Congress on Brain and Behaviour

Thessaloniki, Greece. 28 November - 2 December 2007

Published: 17 April 2008

Annals of General Psychiatry 2008, 7(Suppl I):S285 doi:I0.I I86/I744-859X-7-SI-S285

This abstract is available from: http://www.annals-general-psychiatry.com/content/7/SI/S285

(c) 2008 Fountoulakis et al.; licensee BioMed Central Ltd.

\section{Background}

Obesity, especially central, and the metabolic syndrome are highly prevalent in psychiatric patients. They are mostly attributed to the use of antipsychotic medication and to lifestyle habits and constitute a significant health concern since they seem to be risk factors for rather serious medical conditions.

\section{Materials and methods}

The study sample included 105 patients suffering from schizophrenia (44 females-41.91\% and 61 males$58.09 \%$ ) aged $36.25 \pm 10.03$ (range 19-69) and 156 normal control subjects ( 65 females $-41.66 \%$ and 91 males$58.34 \%$ ) aged $36.03 \pm 11.33$ (range 19-68). Clinical diagnosis was made according to DSM-IV-TR criteria. Height, weight, waist circumference and number of cigarettes smoked daily were recorded. Duration of illness was calculated based on records concerning the age of first onset of psychotic symptoms. Body Surface Area (BSA) and Body Mass Index (BMI) were calculated as well as \% body fat, with the use of LifeWiseTM Body Fat Analyzers No 631525.

\section{Results}

The ANOVA results suggested a significant main effect regarding diagnosis and gender as well as for their interaction. Scheffe post hoc test demonstrated significant differences between patients and controls regarding body weight (women only, $\mathrm{p}=0.002$ ), waist circumference (men $\mathrm{p}=0.002$, women $\mathrm{p}<0.0001$ ), BMI (women only, $\mathrm{p}<0.001$ ), BSA (women only, $\mathrm{p}<0.01$ ) and \% body fat (women only, $\mathrm{p}=0.033$ ), with patients being more obese. The patients also smoked more cigarettes daily (men $\mathrm{p}=0.002$, women $\mathrm{p}=0.016$ )

\section{Conclusions}

The results of the present study corroborate the increased prevalence of obesity in schizophrenic patients, especially female. The interpretation of this finding remains unclear. 